\title{
Sin espacio público no hay ciudad
}

\section{Without public space there is no city}

\author{
Jorge Benavides Solís*
}

Fecha de recepción: 01-02-2016 - Fecha de aceptación: 29-03-2016

Hábitat y Sociedad (ISSN 2173-125X), n. ${ }^{\circ}$ 9, noviembre de 2016, pp. 177-192.

\begin{abstract}
Summary
I have worked and I've posted over the years on the subject, both in the scope of practice and theoretical reflection. With this text, I have the desire to contribute to the enrichment of a wide reflection that make possible better understanding of evolution of public space, or of the city. For this reason, temporary travel to contextualize the evolution which has been a subject of public space, is broad, but with reference to the Western City.
\end{abstract}

Key words

City, Social Transformation, Urban Space, Public Space

\begin{abstract}
Resumen
He trabajado y he publicado durante varios años sobre el tema, tanto en el ámbito de la práctica como en el de la reflexión teórica. Con este texto guardo el deseo de contribuir al enriquecimiento de una amplia reflexión que haga posible la mejor comprensión del proceso de evolución del espacio público, o sea, de la ciudad. Por ese motivo, el recorrido temporal para contextualizar la evolución a la cual ha estado sujeto el espacio público es amplio, pero con referencia a la ciudad occidental.
\end{abstract}

\section{Palabras clave}

Ciudad, Transformación social, Espacio urbano, Espacio público

\footnotetext{
Profesor Titular de Universidad. Correo: benavide@us.es.

1 http://www.abc.es/estilo/gente/20150427/abci-finca-pozuelo-lujo-201504242017.html: «Aquí el único filtro es el dinero», declara una propietaria. 2 http://www.elinmobiliario.com/argentina/desarrollos/buenos_aires_zona_ norte/barrios_cerrados/grondona_y_asociados/nordelta_ciudad_pueblo_1219. html.

3 http:/ / www.idealista.com / inmueble/30343212/?xtmc=1_1_urbanizacion-la-finca-madrid\&xtcr $=0$. Chalet independiente, parcela de $3530 \mathrm{~m}^{2}, 800 \mathrm{~m}^{2}$ construidos, 7 habitaciones, 7 wc, garaje, aire acondicionado, piscina, jardín. Precio $€ 5,9 \mathrm{M}$.
}

La construcción de la ciudad sin espacio público no es posible porque sin él, no hay ciudad. Dicho de otra manera, aunque un asentamiento humano tenga centenares de viviendas, será un simple campamento o una urbanización, tal como se constata por un lado en los asentamientos urbanos ricos (figuras 1 y 2), por ejemplo, en aquellas construidas por empresas inmobiliarias durante las últimas décadas del siglo XX: Walt Disney, Celebration en La Florida (20000 habitantes, 27,34 km²); García Cereceda, la Finca en Madrid ${ }^{1}$ (125 Ha), Nordelta-Tigre ${ }^{2}$ en Buenos Aires, uno de los once "Barrios cerrados" construidos en 1600 ha y otras en todos los países del mundo. Asentamientos humanos sin corazón tal como en 1951 reflexionó el CIAM, porque tienen vida artificial; todo es privado y cercado, sin interacción con el entorno social. Con espacios comunitarios de forma similar a los que tienen los condominios verticales; carentes de equipamientos públicos porque cada parcela dispone de: árboles, jardín, gimnasio, piscina, salones de cine y de ocio para adultos, jóvenes y niños, garajes. ${ }^{3}$ No son ciudades porque la ciudadanía solo es posible ejercerla fuera, no dentro de la urbanización, pues en esta su gestión general incluida la seguridad puede estar o está encargada a una empresa con un gerente; no a los representantes de los ciudadanos sino a los contratados por los propietarios.

Las gated communities de Estados Unidos, los fraccionamientos cerrados 


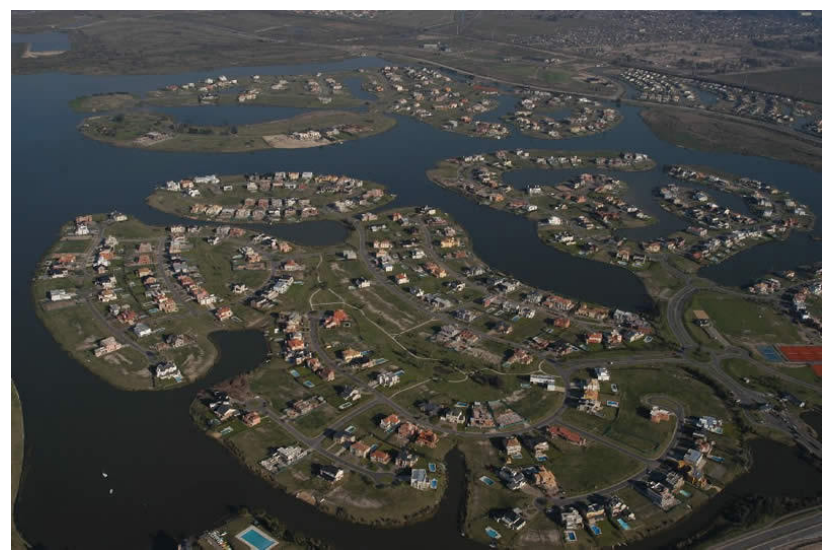

Figura 1. Nordelta, Buenos Aires Norte. Fuente: disponible en www.elinmobiliario.com de México, las Geschlossene Wohnkomplexe de Alemania, los countries de Argentina, los parcelamentos fechados del Brasil, no son ciudad y tampoco son parte de ella porque expresamente, sin espacios públicos, no son urbanizaciones hechas para ser ciudad.

En el otro extremo, los asentamientos de los ciudadanos pobres (figuras 3 y 4) tampoco son ciudad: las grandes favelas (Brasil), los macro slums (India), los barrios marginales (Colombia), los asentamientos informales (Perú) o los barrios de chabolas (España), con baja densidad de vivienda, con un alto índice de ocupación de las mismas; con escasos espacios comunes, sin equipamientos, con ausencia o precarios servicios públicos, con pésimas condiciones ambientales, con altos índices de inseguridad, pero, paradójicamente, con frecuentes microcosmos de ayuda mutua. No son ciudad pero sí son parte o son medianos y grandes apéndices de ella. Sin la ciu-
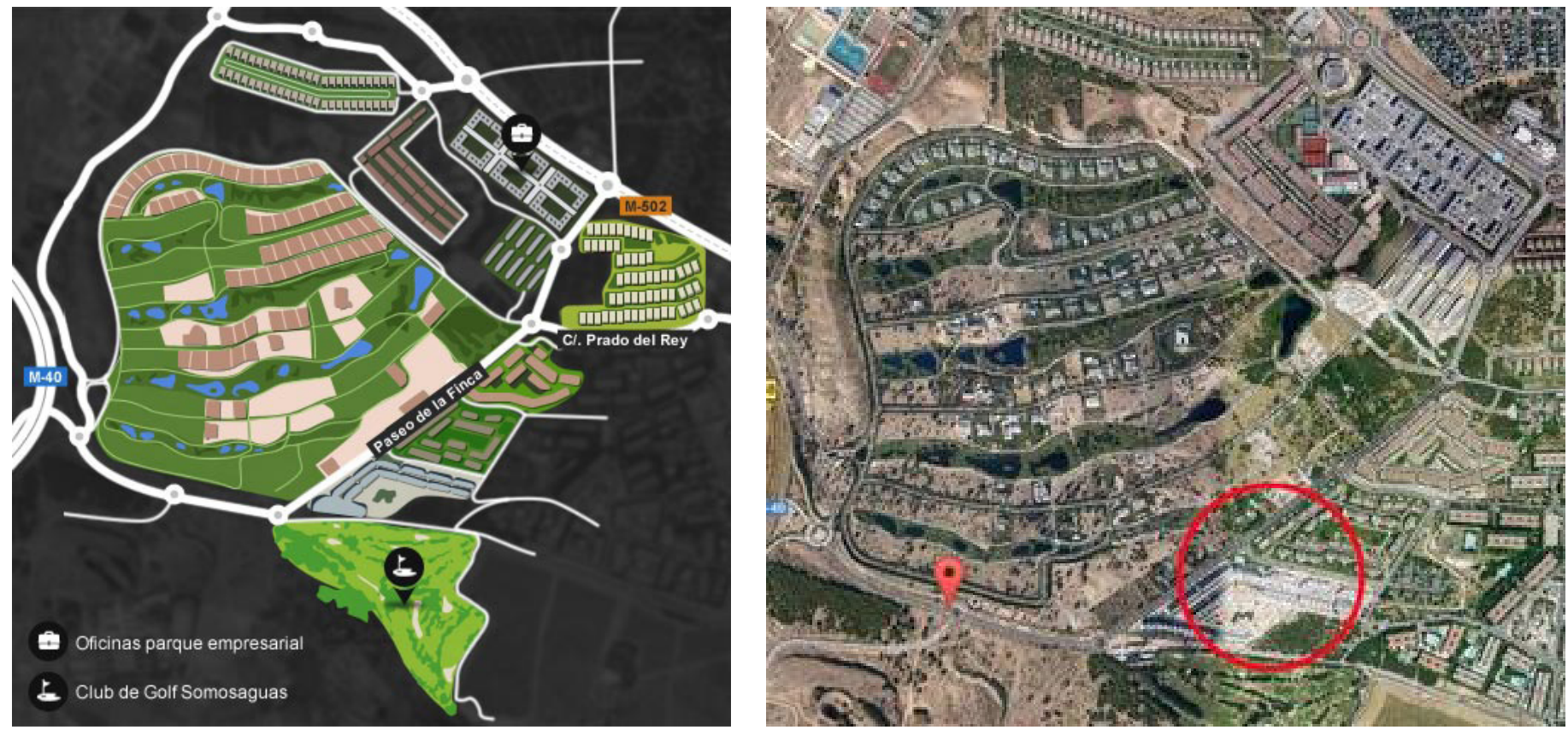

Figura 2. La Finca, Madrid. Fuente: disponible en http://www.elconfidencial. com/empresas/2016-04-27/la-fincaprocisa-nmas 1 -axiare-varde-venta-susana-cereceda-lvis_1191232/.

$4 \quad$ En uno de los vertederos más grandes de Centroamérica, La Chureca, Nicaragua hay más de 2000 casas de hojalata y cartón construidas entre la basura. Ninguna con agua, luz ni servicios básicos. Ver Waste Atlas The world`s 50 biggest dumpsites 2014. 5 La favela Paraisópolis de Sao Paulo, tiene origen en la lotización privada de la hacienda Morumbi hecha en 1921. Debido a los incumplidos ofrecimientos del propietario, a partir de fines de los años sesenta del s. XX se desata la ocupación informal. Actualmente tiene cerca de 80000 habitantes sobre un área de 108,4 ha. dad no se explicarían; más todavía cuando la vinculación directa se da con las macrociudades, incluso a través de sus vertederos. ${ }^{4}$ Su relación de dependencia fluye por predeterminados cauces capitalistas de desigualdad y de injusticia, en los modos de producción y en las formas de distribución, también espacial. Estas no-ciudades se localizan donde los planes y las leyes lo impiden o no lo prevén y por ello carecen de espacio público, entendido en su más amplio significado. No ejercen la civilidad ni colaboran en la construcción de la opinión pública.

En São Paulo, uno de los más lujosos condominios, Jardim Vitória Régia, Paço dos Reis e Portal do Morumbi, limita con la segunda favela más grande del Brasil después de Rocinha en Rio de Janerio, eufemísticamente bautizada como Paraisópolis. ${ }^{5}$ Los trabajadores pobres de las favelas, con un alto muro en medio, comparten el suelo con empresarios ricos, en condiciones de desigualdad e injusticia, de la misma forma que lo hacen al interior de la sociedad construida; sin que por ello, actualmente, se avizoren, ni mucho menos, revoluciones similares a las del siglo pasado. 


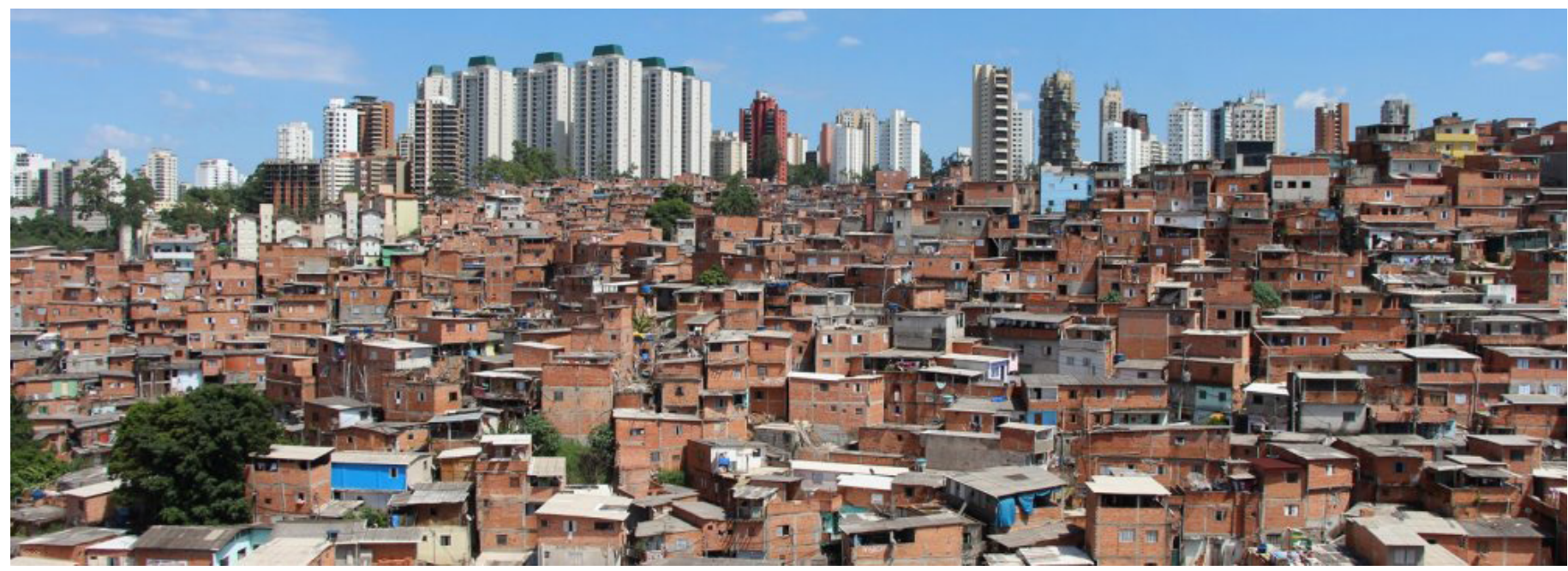

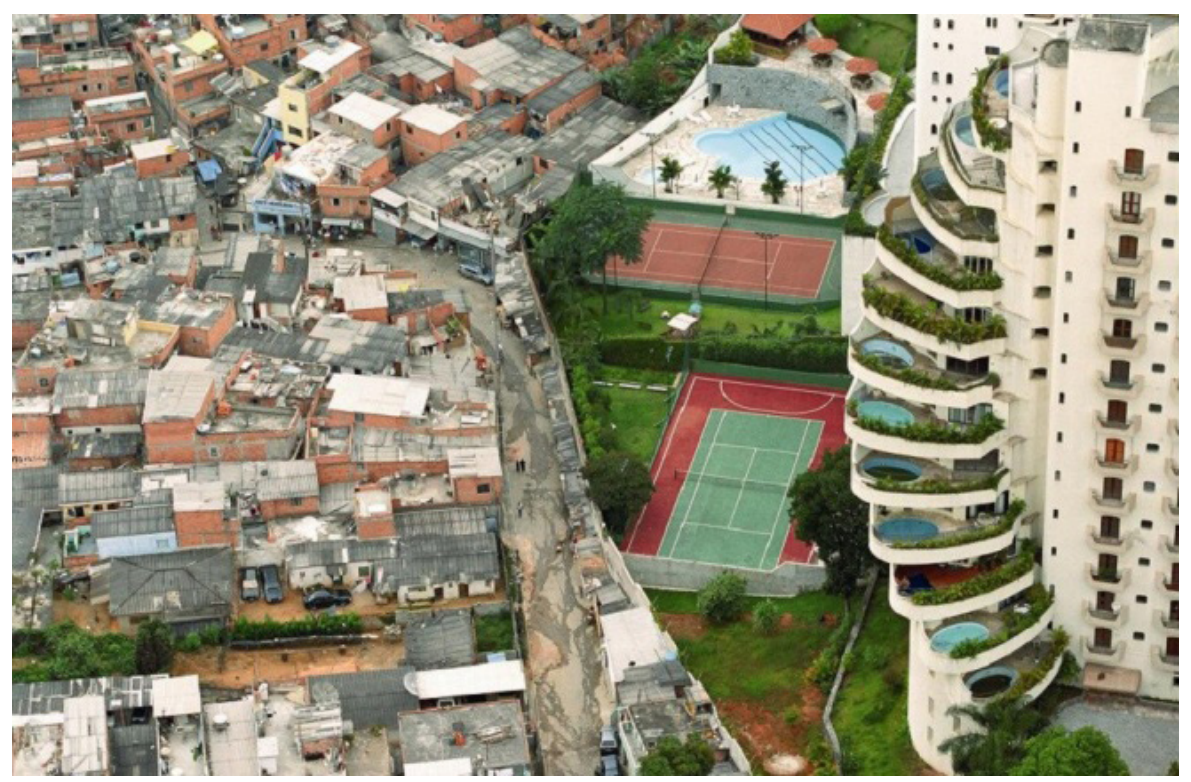

El modo de producción ha cambiado. La incorporación de las TIC, hasta en el ámbito más íntimo de la vida, está desatando transformaciones cada vez más numerosas y rápidas en todos sus ámbitos. Ya no hay clases sociales. El trabajador pobre, antiguo proletario o lumpen ahora se diferencia del rico solamente por el nivel de acceso y la capacidad de consumo, no por la ubicación dentro del proceso de producción. Google ha regalado ${ }^{6}$ miles de teléfonos móviles a los más pobres de la India porque estos, al usarlos, proporcionan, sin saberlo, gratuitamente, información útil para la industria farmacéutica y otras empresas. Es el nuevo tipo de esclavitud virtual.

Los dos extremos señalados, gated communities y favelas, con sendos matices, aquel rico por exceso y el pobre por defecto, tal como aparecen a principios del siglo XXI, son el evidente testimonio material de la extrema desigualdad e inequidad imperantes en el mundo.

La desigualdad dentro de la ciudad (pobres y ricos) no es nada nuevo. Los pobres en calidad de esclavos, siervos, proletarios, trabajadores temporales, jornaleros o precarios, siempre han estado presentes en la ciudad. La novedad actual es la magnitud. Los millones de pobres son más pobres y el número de ricos es cada vez menor porque la riqueza está más concentrada. La fortuna de Jorge Paulo Lemann, el más rico del Brasil (24000 M. de dólares), es similar al presupuesto del municipio de São Paulo, ciudad de más 11 millones de habitantes.
个 Figura 3. Paraisópolis. Gran Favela. Sao Paulo. Fuente: disponible en http:// es.brasil247.com/.

$\leftarrow$ Figura 4. Condominios de lujo, Jardim Vitória Régia, Sao Paulo. Fuente: Tuca Vieira http://www.tucavieira.com. br/A-foto-da-favela-de-Paraisopolis.

6 http://www.elconfidencial.com/tecnologia/2015-12-04/filantropia-o-negocio-zuckerberg-responde-a-las-criticas-sobre-su-donacion_1113703/. Otro ejemplo más de aparente filantropía. 
Nunca antes la población rural había sido equivalente a la urbana como se anunció en 2008 cuando el planeta estaba habitado por 6709132764 personas. En 2016 habrá mil millones más. Según las Naciones Unidas, dentro de 20 años, solamente 1 de cada 4 habitantes del planeta será rural. ¿Hará falta mano de obra para cultivar? No es fácil responder. En cualquier caso, los consumidores urbanos serán tres veces más que los de hoy.

De lo anterior es posible formular una conclusión de partida: La construcción de la ciudad se asemeja a la construcción de la sociedad. Ninguna de las dos nos viene dada. Tampoco cada una permanece igual. Las dos están sometidas a un proceso de cambio sistémico (interdependencia, inter-acciones) y holístico (que toma en cuenta el todo, ahora, el planeta, no solamente la parte ya sea país o continente) no predeterminado. Están en constante cambio.

Para analizar la forma de construcción de la ciudad actual, es imperativo vincularla a la evolución de la sociedad, a su estructura económica, a sus formas de gobierno, a sus instituciones y a sus paradigmas culturales. Si no se procediera así, nos ubicaríamos en el tradicional ámbito reduccionista, disciplinar, especializado, parcial, como lo explica Morin; siendo como es la ciudad: un todo. Por lo tanto, conviene pensar sobre: ¿Cuál es y dónde se encuentra el origen de la ciudad europea? ¿En qué contexto histórico, con qué contenido y con cuál significado? Tomando en cuenta la constante dicotomía social no superada: ¿Cuáles han sido las consecuencias de la expansión de la ciudad en diferentes períodos históricos? ¿En qué sentido y medida, la ciudad de los ricos y los pobres es una particularidad contemporánea? ¿Cómo se construye la ciudad y quiénes participan en ello? ¿El espacio público está en peligro de extinción? La ciudad tal como hoy la entendemos ¿está llamada a desaparecer? O ¿ está destinada a diluirse o transformarse con otro contenido y con distinto significado?

La sociedad humana comenzó a construirse cuando el sapiens ya tenía conciencia de la muerte, del tiempo y del espacio. En la Cueva Chauvet (figuras 5 y 6), Francia, descubierta en 1995, dejó su más antiguo testimonio artístico conocido. Se remonta a 30000 años. Todavía sobrevivía de la caza y de la recolección de productos silvestres. Iba en grupo de 20 personas, con una máxima esperanza de vida de 30 años y sometido a una jerarquía simplemente funcional, bajo la dirección del líder, seguramente el más fuerte, sagaz, intuitivo y astuto para enfrentar las duras condiciones de la supervivencia y, como además comía carne, por el tiempo necesario para su digestión, mayor al de los frutos vegetales, podía desplazarse a mayores distancias, generalmente buscando y siguiendo el curso de los ríos. Cuando utilizó las cuevas como refugios (espacio natural interior) ya era capaz de hacer el fuego, la llama, y agruparse alrededor de ella; así como de representar los animales en su entorno, vivos, no muertos, con un extraordinario realismo debido al tiempo dedicado a la observación, primera forma de investigar y a sus aguzados sentidos desarrollados para ver, oír y oler, útiles para reconocer la fauna, la flora, la naturaleza que aprovechaba para sobrevivir. No existen testimonios anteriores para explicar esas pinturas rupestres de un extraordinario realismo hechas con líneas y gamas de color.

En 1994 se descubrió que veinte mil años después de la construcción de las cuevas, pero cuando el sapiens todavía no había llegado a conocer los metales, fue capaz de construir en el espacio natural abierto un conjunto monumental pétreo no habitable, Gobelki Tepe (figuras 7 y 8), pues no se han encontrado vestigios que testimonien lo contrario, 

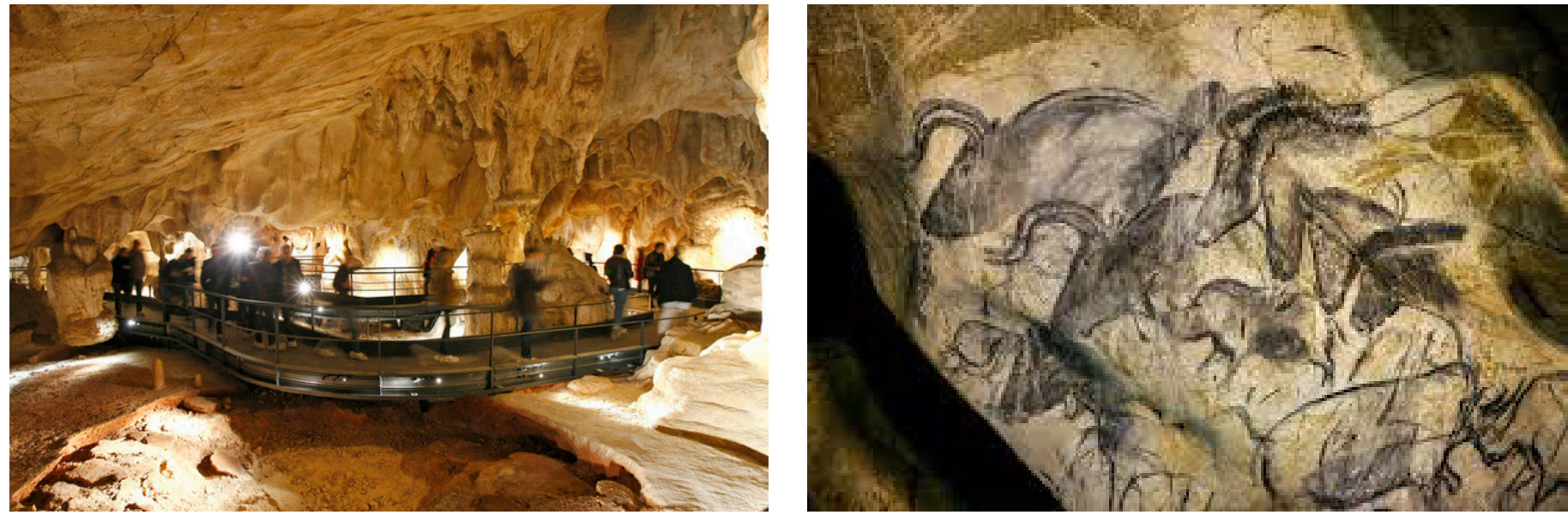

útil solamente para celebrar en grupo, los festines celebrativos gregarios vinculados a lo desconocido, a lo sagrado. Su construcción supone un conocimiento tecnológico que hizo posible trasladar los monolitos de hasta 10 toneladas desde más de $400 \mathrm{~m}$ para lo cual eran necesarias unas 500 personas. En ellos se encuentran representados numerosos animales existentes en la zona en alto relieves o con incisiones. La sociedad paleolítica ya había conseguido organizarse bajo la presencia de una casta sacerdotal.

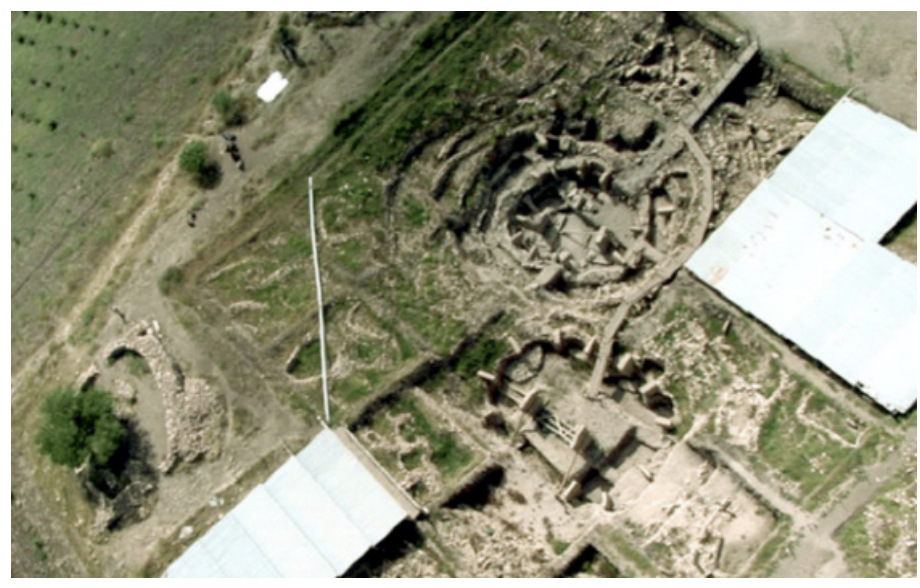

En 1961 se había descubierto Chatal Huyuk (7400-6200 a. C.) un asentamiento de considerables dimensiones que estuvo ocupado, según los arqueólogos, por hasta 6000 personas (figura 9). De los 139 edificios estudiados por J. Mellaarte (1967) al parecer 40 pudieron ser santuarios o recintos religiosos. Se trata de un conjunto único de casas agrupadas sin calles y sin espacios interiores de privacidad, con pinturas murales, relieves, esculturas de características prácticas, simbólicas y artísticas. La sociedad con jerarquía organizada básica había llegado a ocupar de manera permanente el suelo. Poco a poco, con el tiempo, se irá definiendo y constituyendo el estado que aparecerá de cuerpo entero en la antigua Grecia.

Hasta aquí, durante un proceso de veinte mil años aparecen como constantes la conciencia del tiempo, del espacio, de lo sagrado y de lo artístico y, por otra parte, la idea de la posesión, no de la propiedad, de lo colectivo antes que de lo personal, de lo nuestro antes que de lo mío. Es posible constatar que el sapiens desarrollaba una acción natural sistémica y holística: el todo (grupo), la parte (el individuo) y el entorno (la
Figuras 5 y 6. Cueva de Chauvet. Fuente: disponible en http://ruta-33.blogspot.com/2016/07/las-pinturas-rupestres-de-la-cueva-chauvet-pont-darc-francia. html.
Figuras 7 y 8. Gobelki Tepe 111000 a.C). Fuente: disponible en http://www. nationalgeographic.com.es/historia/ grandes-reportajes/gobekli-tepe-el-primertemplode-la-historia_6363. 


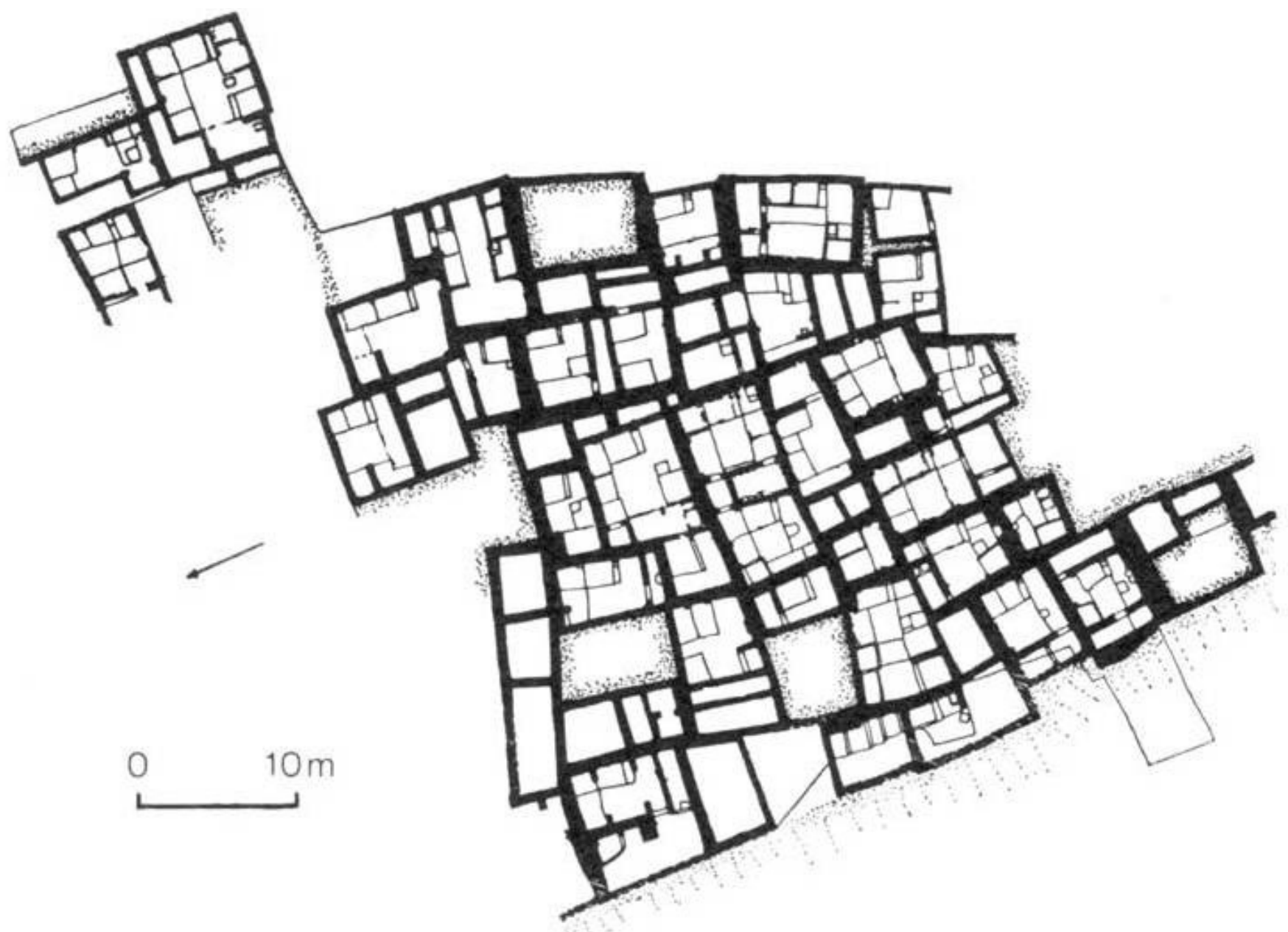

Figura 9. Catal Huyuk (7400 y 6200 a. C.) Fuente: disponible en https:// es. pinterest.com/schaukin/catal-huyuk/. naturaleza) interrelacionados. El espacio existente sería colectivo mas no público; por lo tanto, la ciudad aún no existe a pesar del sedentarismo, de los beneficios de la agricultura y del uso del metal.

El espacio público proviene de hace 3500 años. Su proceso culminó en la Atenas clásica (figuras 10, 11 y 12). Será opuesto al espacio particular. Corresponderá a parte del espacio sagrado, del ágora, y por extensión de aquellos espacios no construidos (calles, caminos) de comunicación de esta con las viviendas. Es decir, bajo un sistema productivo esclavista o, lo que es lo mismo, el espacio público aparece cuando la organización de la sociedad se hizo compleja y surgió el compromiso de los habitantes con la polis, lo cual no se explica sin un soporte filosófico o carente de un sistema de ideas que haga posible la concepción de una vida virtuosa, justa y por ello incluso bella.

Figura 10. Atenas. Fuente: disponible en http://sobregrecia.com/2008/03/15/ el-agora-de-atenas/. 

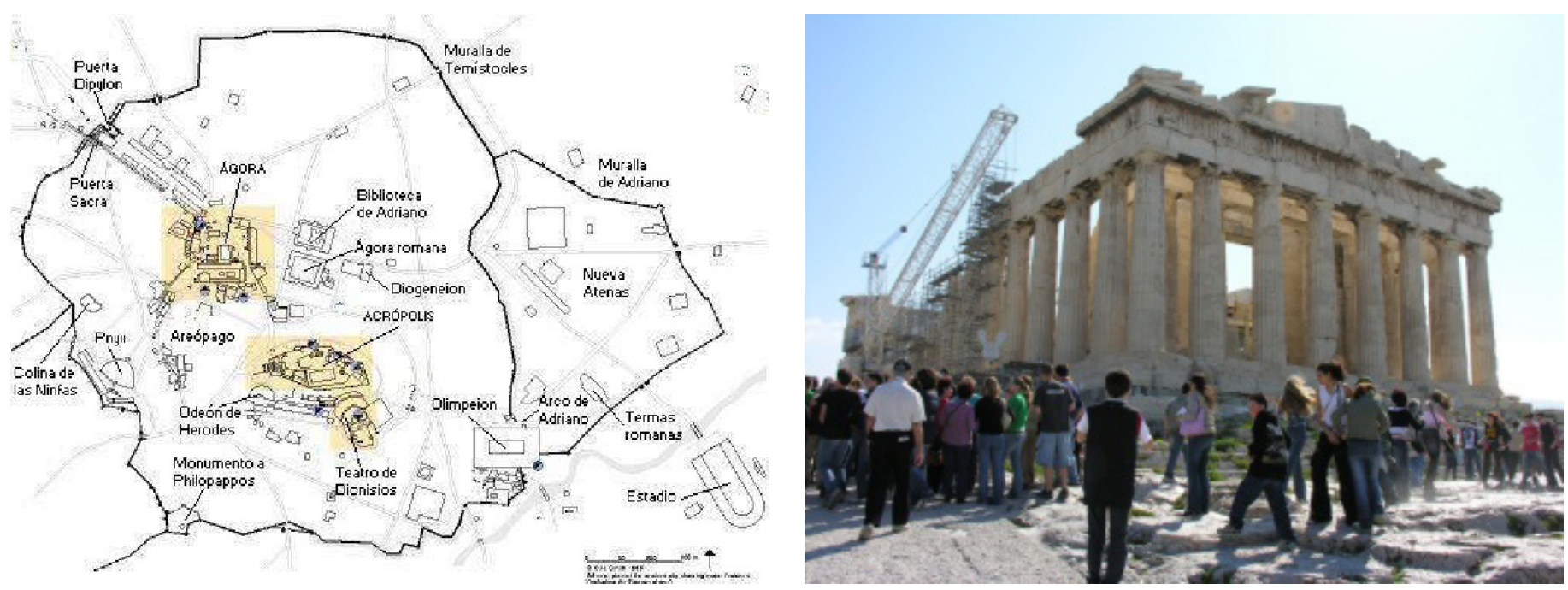

Para los griegos, la polis era lo que hoy podríamos entender como la ciudad total, lugar de interrelación interna y externa del territorio en el que residen todos los miembros de una sociedad cuyo objetivo es hacer posible su vida con justicia, felicidad y otros valores que están en el ámbito del pensamiento abstracto.

Platón en tres de sus libros, en orden de cuando los escribió, describe la idea de tres ciudades: Calípolis (ciudad bella), Atlántida (ciudad ideada) y Magnesia (ciudad como debería ser fundada). Constituyen una reflexión sobre "el principio de la vida social", es decir, del vínculo que interrelaciona a la sociedad conformada por individuos, familias, fratrías, con el Estado, con la polis.

(...) la ciudad nace, en mi opinión, por darse la circunstancia de que ninguno de nosotros se basta a sí mismo, sino que necesita de muchas cosas. Por ninguna otra razón se fundan las ciudades (...) Se edifica desde sus cimientos según nuestras necesidades (La República 369 b, c, d).

La primera y mayor de ellas es la provisión de alimentos para mantener existencia y vida; la segunda, la habitación; la tercera, el vestido y cosas similares; dice Platón:

[Según Aristóteles] la ciudad tiene necesidad seguramente de la propiedad, pero la propiedad no es ni remotamente parte esencial de la ciudad, por más que de la propiedad formen parte, como elementos, seres vivos. La ciudad no es más que una asociación de seres iguales, que aspiran en común a conseguir una existencia dichosa y fácil (Libro IV. Capítulo VII. Política).

De lo cual es lógico deducir, que la ciudad construye la sociedad.

Otra cosa sucederá en el Imperio romano. Al Ágora, lugar del ciudadano, la hizo Foro, espacio de los edificios representativos de culto, administración, comercio y ocio para reproducir en él la imagen del Estado, del poder en todas las ciudades del Imperio. Imperio que lo institucionalizó todo, respaldándolo con manuales y códigos, incluyendo el de la propiedad.

El espacio público en la ciudad fue convertido en el marco de la arquitectura institucional, monumental, que utiliza un "orden" estético: forma, dimensiones, escala, proporción y, a la vez, simetría.

La mayoría de las calles de Roma, capital del Imperio (figuras 13- $\kappa$ Figura 11. Atenas S. II d. C. Fuente: disponible en http://www.geocities.ws/ rolandcast/atenas.html.

个 Figura 12. Atenas. Acrópolis. 
16) eran espacios residuales de unos $3 \mathrm{~m}$ de ancho delimitadas por insulae de $21 \mathrm{~m}$ de altura (7 plantas) establecido como máximo por $\mathrm{Au}-$ gusto y disminuido a $18 \mathrm{~m}$ por Trajano. Las dos únicas vías, llamadas Sacra y Nova, que atravesaban el Foro, tenían apenas $6 \mathrm{~m}$ de ancho. Por ellas desfilaba el ejército al volver de sus conquistas.
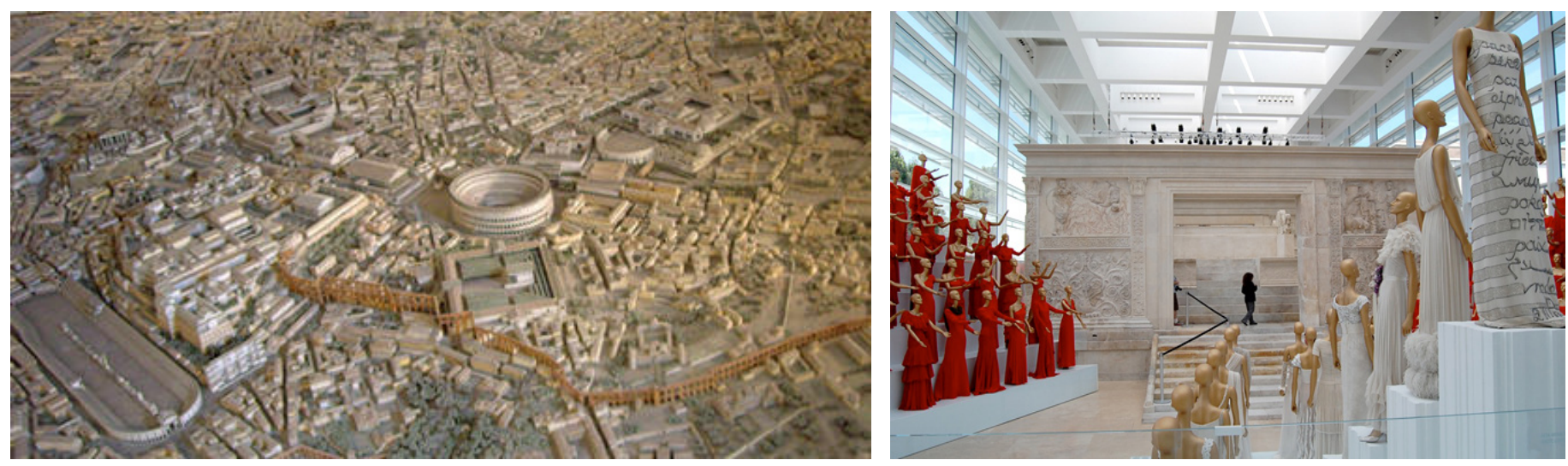

个 Figura 13. Roma imperial. Maqueta. Fuente: disponible en http://www.museociviltaromana.it/collezioni/percorsi_ per_sale/plastico_di_roma_imperiale.

入 Figura 14. Valentino Ara Pacis. Fuente: disponible en http://www.stylosophy. it/foto/valentino-ara-pacis_533_3.html.
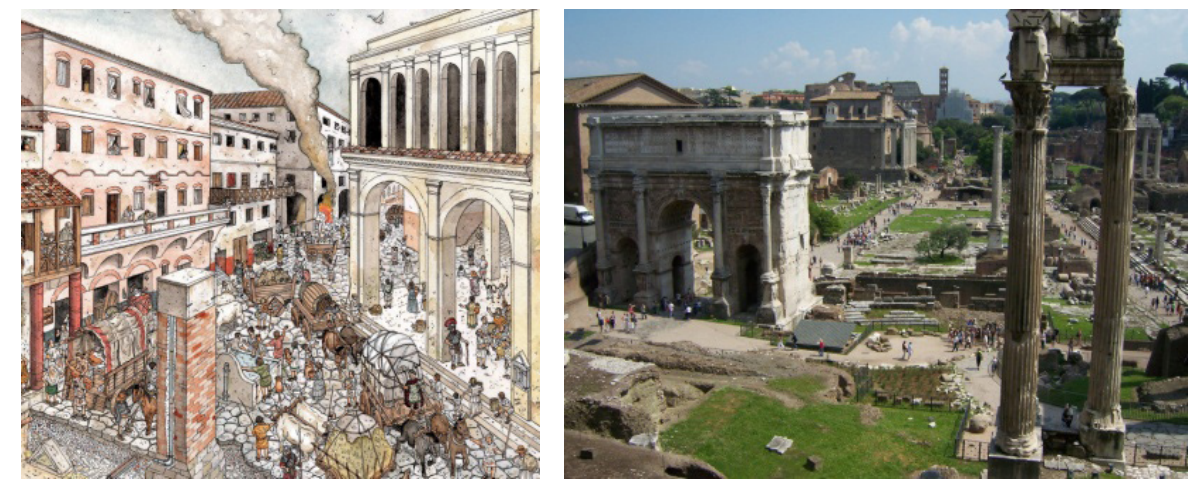

个 Figura 15. Reconstrucción de una calle del centro de Roma. Fuente: disponible en http://historiaantiguaromana.blogspot.com.es/2007/12/insulae.html. 入 Figura 16. Via Sacra. Fuente: disponible en http://ciceronroma.blogspot.com. es/2007/05/el-foro-romano-la-via-sacra.html.

A diferencia de los griegos, durante el Imperio romano el Estado funda y construye la ciudad sin apoyarse en una teoría social. Si la ciudad es de nueva fundación, según Polibio (200-118 a.C), se utiliza un modelo derivado del campamento romano y si la urbs ya existe, se implanta las dos vías principales: cardo y decumanus y en su intersección se construyen los edificios institucionales de culto, administración y ocio, es decir estatales: el foro.

El sistema de ciudades de todo el Imperio, unidas por un sistema de vías principales, organizó el territorio haciendo posible la vinculación entre centros de producción agrícola y extractiva con los centros de consumo. "El comercio tuvo su máximo apogeo con la pax romana en el siglo II. La red viaria era de unos $80000 \mathrm{~km}$ de carreteras pavimentadas; las calzadas. La famosa frase de que todos los caminos llegan a Roma resulta cierta. Cientos de vías se unían a 20 principales que iban desde cualquier punto del Imperio a Roma. Algunas tenían 7,5 m de anchura. Cada mil pasos, una milla romana, $1480 \mathrm{~m}$ se colocaba un $m i$ liarium; roca cilíndrica de unos $2 \mathrm{~m}$ de altura, $0,5 \mathrm{~m}$ de diámetro y un peso de unas $2 \mathrm{t}$, que indicaban la distancia entre las poblaciones, los logros del Emperador que gobernaba en ese momento, quien la había construido, si había sido reparada restituit, si la calzada era de grava vía 
glarea, si estaba pavimentada vía strata. También contaron con túneles, puentes, cualquier obra de ingeniería que fuera necesaria para facilitar el camino (...). A Roma llegaban un total de 372 vías desarrolladas a partir de 20 calzadas principales. Desde Gades (Cádiz) por la Vía Augusta se recorría toda la costa hispana, la francesa y la italiana donde recibía el nombre de Vía Aureliana que hasta ahora existe en Roma. ${ }^{7}$

A partir de varias referencias se deduce que la construcción de la ciudad y la ordenación del territorio eran de competencia estatal y el Estado había definido las diferencias entre lo rústico y lo urbano, lo particular, lo privado, lo público y otros matices de la propiedad, del uso y del usufructo que consta en leyes específicas. De cualquier modo, había cosas que estaban fuera del comercio: res quarum commercium non est, o res extra commercium, tales como: a) las cosas que se consideran comunes a todos los hombres, como el aire o el mar; $b$ ) las que se considera que pertenecen a los dioses, como los templos o las ofrendas; $c$ ) el agua, que no puede ser objeto de apropiación privada; $d$ ) las que son del pueblo romano, como las calles, las vías, las plazas públicas o las murallas (Adame, 2009). Obras de enorme magnitud si se piensa por ejemplo en los 11 acueductos principales de Roma construidos entre el 312 a. C y el 20 d. C.

Pero el Imperio entra en decadencia porque los esclavos se liberan, la producción decae y las finanzas del Estado entran en una crisis constante e irreversible (Garía, 2014), con lo cual, emerge un nuevo sistema de producción denominado por Marx como el feudalismo: el siervo ocupa el lugar del esclavo y el señor feudal el del patricio. Al Andalus es una extraordinaria excepción no integrada aún en la historia de Europa.

La producción comenzará a depender preponderantemente de la agricultura, o sea, del campo, porque las grandes ciudades, centros de consumo, se abandonan. Serán reemplazadas por un endeble sistema de burgos ubicados estratégicamente que marcarán en el futuro la importancia del comercio y de las rutas entre el sur y el norte de Europa.

En estas circunstancias destaca el protagonismo de la Iglesia católica, que aprovecha la tradicional confluencia del poder civil y religioso que se daba en el Imperio romano. La nueva organización se hará patente en la estructura de las ciudades, el castillo, el palacio nobiliario, la iglesia y el mercado. Marcarán la centralidad del caserío y darán lugar a la ciudad europea tal como lo explican Henry Pirenne (1983) y Max Weber (1987). El espacio público urbano tendrá una disminuida presencia y significado civil.

La organización feudal de la sociedad también entrará en crisis cuando los siervos disminuyen considerablemente, pues adquieren la posibilidad de vender "libremente" su fuerza de trabajo, los bancos hacen préstamos, el comercio a distancia tiene un gran desarrollo debido a su dimensión mundial, tal como lo explica F. Braudel, el antropocentrismo hace posible la comprensión del mundo apoyándose en la razón y en la experiencia; además, difundirlas; todo lo cual, precisamente, explicará el Re-nacimiento de la cultura clásica: una nueva organización social que dará lugar a una nueva forma de construir la ciudad.

León Batista Alberti con sus diez libros de Arquitectura emuló a Vitruvio, pero sin profundizar en una teoría general, ni de la sociedad ni de la polis, como hicieron los griegos. La ciudad la concibe como un marco general abierto cuya calidad dependerá de la técnica constructiva y del arte de hacer Arquitectura, gracias a la conciencia de espacio, de medida y de perspectiva, de vista, de proximidad y de lejanía; cuestiones que más tarde serán investigadas y desarrolladas durante el período barroco cuyo inicio, según Gideon (1984), empieza con la inter-

7 http://www.traianvs.net/index.php. Consulta: diciembre de 2015. 
vención papal en Roma. ${ }^{8}$ La Reforma de Lutero avanzaba con éxito en la Europa central y del norte.

Se trataba de la aplicación de una técnica de intervención en la ciudad construida, ya ensayada por Alberti en Pienza (1459) (figura 17), en Roma cien años después a una escala mayor (figuras 18 y 19), con objetivos ideológicos claramente previstos para hacer posible la presencia del fervor, la expresión popular tradicional y religiosa en las ca-
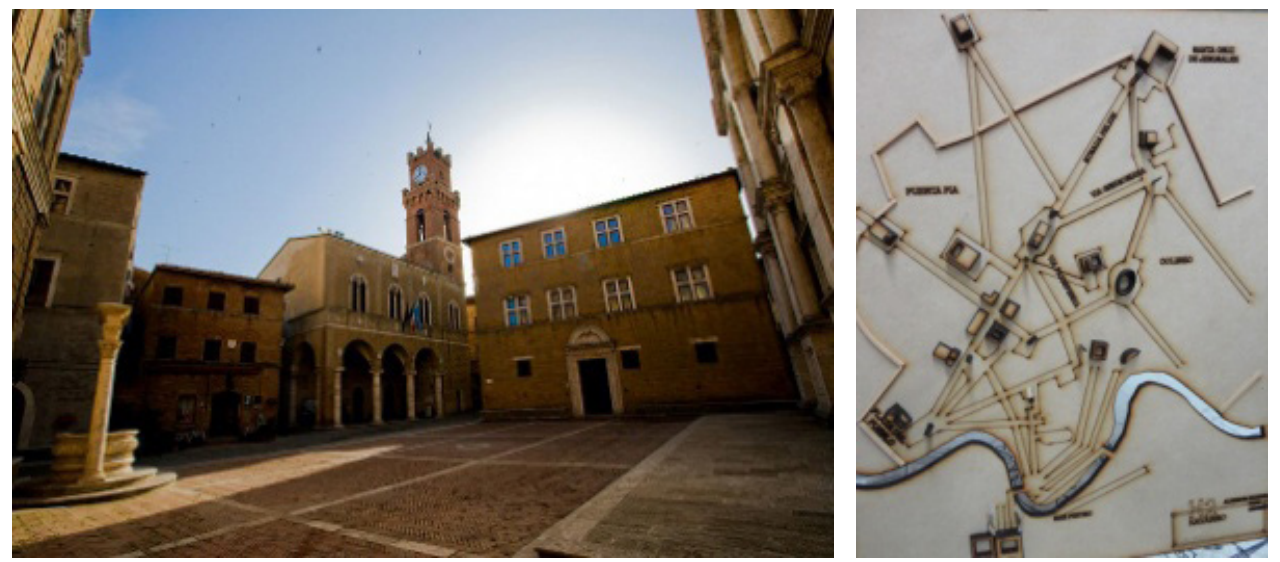

lles. Las fachadas de las iglesias asemejaron retablos pétreos sacados desde el interior, al que al mismo tiempo, consiguieron hacerlo un espacio deslumbrante, teatral, dinámico, gracias a la utilización de la luz como material estético. La capital de los Estados Pontificios debía ser: simbólica y sagrada, edificada in majoren Dei et Ecclesiae gloriam.

个 Figura 17. Pienza. Fuente: disponible en http://www.aboutsiena.com/sobresiena/palacio-piccolomini-pienza.html.

入 Figura 18. Roma de Sixto V. Fuente: disponible en http://arqlopezcoda. blogspot.com.es/2015/07/interpretacion-del-plan-de-sixto-v-para.html.

$\rightarrow$ Figura 19. Piazza del Popolo. Fuente: disponible en http://noticias.arq. com.mx/Detalles/13594.html\#.WE$\mathrm{KU} 3 \mathrm{I}_{\mathrm{Z} P y \times 8}$

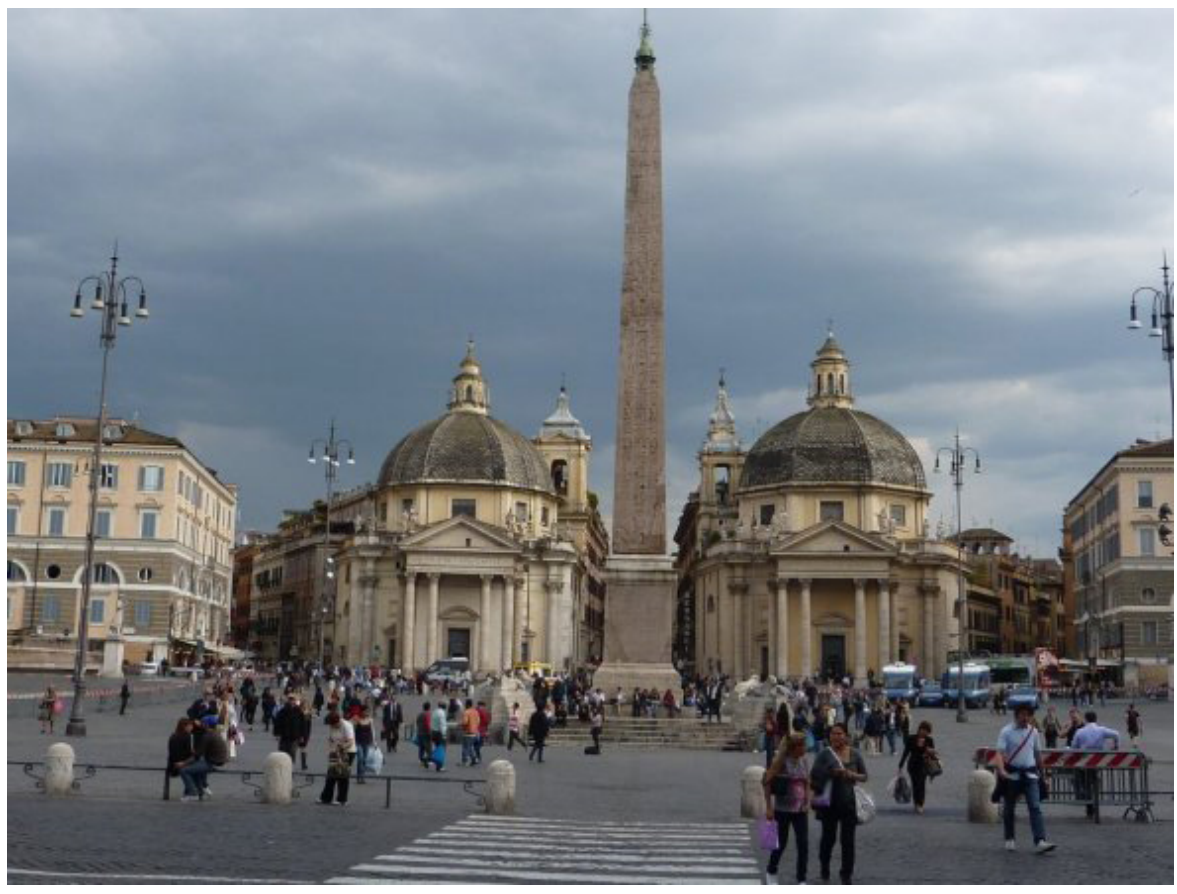

La ciudad tenía las connotaciones de una obra de arte, por lo tanto, debía ser bella y el espacio público construido por las élites, un escenario adecuado. Resultaba ser una ciudad construida sin necesidad de ciudadanía, en otras palabras, sin demos, pero con la participación de la burocracia, un sector de la administración que comenzó a crecer de forma considerable. Así se procedió en Europa durante un prolongado periodo aunque con diferentes matices y resultados, según el contexto de cada país, hasta que el proceso fue transformado por la Revolución francesa (1789).

El Nuevo Régimen en Francia dio lugar al París de Haussman ${ }^{9}$ (figuras 20, 21 y 22) con una nueva tipología de vía: los bulevares largos, arbolados y anchos; con jardines, plazas, parques, bosques, distritos, equipamientos; con edificios civiles de igual altura e institucionales con escala monumental. 


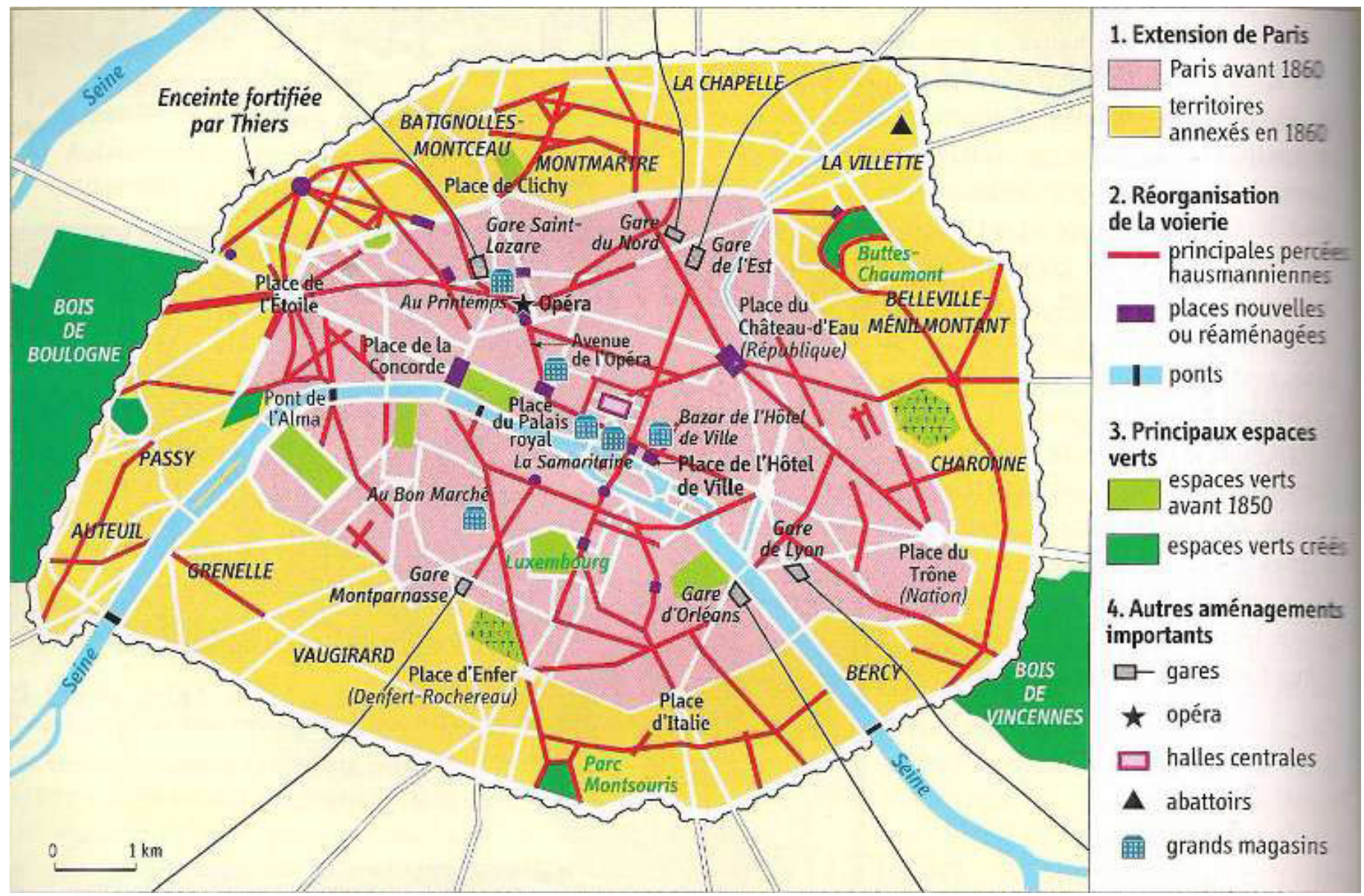

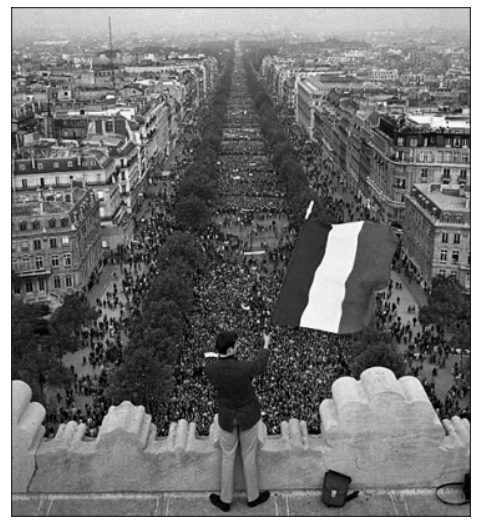

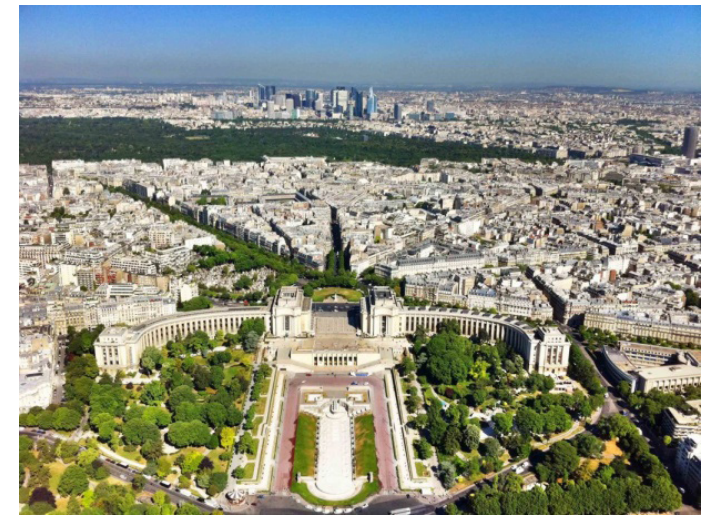

Los avances técnicos de la primera revolución industrial habían hecho posible la "ciudad luz", según una decisión del gobierno, para beneficiar tanto a los ciudadanos como a los inversores; los primeros que, en tanto pueblo, le dio nuevo significado al espacio urbano, y los segundos que comenzaron a ser protagonistas cada vez más determinantes en la construcción de la ciudad física. La monarquía absolutista había dado paso a la república como nueva organización del Estado que junto con la transformación industrial dio lugar al planteamiento de una alternativa revolucionaria (anarquismo, marxismo) y otra social demócrata. En estas circunstancias, los espacios públicos serán definidos legalmente en el Código Napoleónico (modernización del Código Romano); serán aquellos fuera de la línea que delimita la parcela (privada) hacia la calle.

La ciudad hasta entonces se había expandido de manera contigua, compacta y continua, por eso yo la he denominado de las 3 C. Los edificios y las casas se construían contiguos a las vecinas, lo cual determi-
个 Figura 20. París. Transformación siglo XIX. Fuente: disponible en http://www. neufhistoire.fr/articles. php? $\operatorname{lng}=f r \& p g=1338 \&$ tconfig $=0$.

$\leftarrow$ Figura 21 . París. Espacio escenario de manifestación popular. Fuente: disponible en https: / / s-media-cache-akO.pinimg.com/originals/23/40/ce/2340ce Oefe80a54b344667977e3 $115 \mathrm{db} . j p g$.

$\leftarrow$ Figura 22. París. Bulevares y espacios verdes. Fuente: disponible en http://megaconstrucciones. net $/$ ? construccion=paris . 
$\downarrow$ Figura 23. Calle Imagen, Sevilla. Fuente: fotografía del autor.

\ Figura 24. Avenida Miraflores, Sevilla. Fuente: disponible en http:/ / sevillanadas. blogspot.com.es/2009/09/unpaseo-por-la-sevilla-de-los-60. html. naba la compacidad y a su vez la continuidad siempre con un marcado borde concebido como límite entre la ciudad y el campo.

Con el crecimiento de la industria, debido al avance de la ciencia y de la técnica, las funciones de la ciudad fueron incorporando actividades antes inexistentes y satisfaciendo nuevas demandas de servicios y de consumo. En este contexto surgió la modernidad en arquitectura, primero vinculada a las vanguardias (ausencia de decoración, nuevas técnicas y materiales) y luego al Movimiento de la Arquitectura Moderna en cuyo último congreso se aprobó la Carta de Atenas (1931). Durante la posguerra en parte se convertirá en la doctrina urbanística, y en otra aún vigente, en principios para redactar los Planes Generales de Ordenación Urbanística. La vía sustituyó a la calle y el bloque aislado diluyó la manzana y cuando se dejó la planta baja libre como recomendó Le Corbusier, en años posteriores llegará a ser un espacio cuando no vacuo, conflictivo.

El espacio urbano dejó de ser blanco (público, no construido) y privado (negro); comenzó a incluir el gris como expresión de un nuevo tipo de espacio urbano, aquel espacio comunitario o compartido, con frecuencia descuidado por los usuarios y por el Ayuntamiento.

Aquí identifico la ubicación del punto de inflexión a partir del cual el espacio urbano perderá escala, proporción, armonía, calidad, tal como lo expresará en un magnífico artículo Bernard Huet en 1985, y desaparecerán los planes de embellecimiento urbano o equivalentes. Desde entonces será posible constatar que la ciudad se hará cada vez más fea. La calidad del espacio público empieza a degradarse por ser el simple resultado de cuantificaciones predeterminadas (coeficientes y estándares).

En los años setenta habían coincidido los cuestionamientos a los principios de la arquitectura moderna y el movimiento La Tendenza (Venturi, 1966, 1969), que rescata el valor de los tejidos urbanos, de las tipologías y de los "elementos primarios" obviados completamente por la Carta de Atenas. Además en estos años se inició la introducción de la Tecnologías de la Información de la Comunicación (TIC) ahora infiltradas hasta en los más escondidos del ámbito más íntimo. El primer ordenador personal había salido a la venta en 1971.

Los polígonos industriales y residenciales en los ensanches de la ciudad cedieron el protagonismo a los centros históricos hasta entonces sometidos a irreversibles intervenciones dañinas bajo los principios precisamente del Movimiento Moderno (figuras 23 y 24). Se rompieron los tejidos, se alteraron las manzanas, la unidad dentro de la dife-
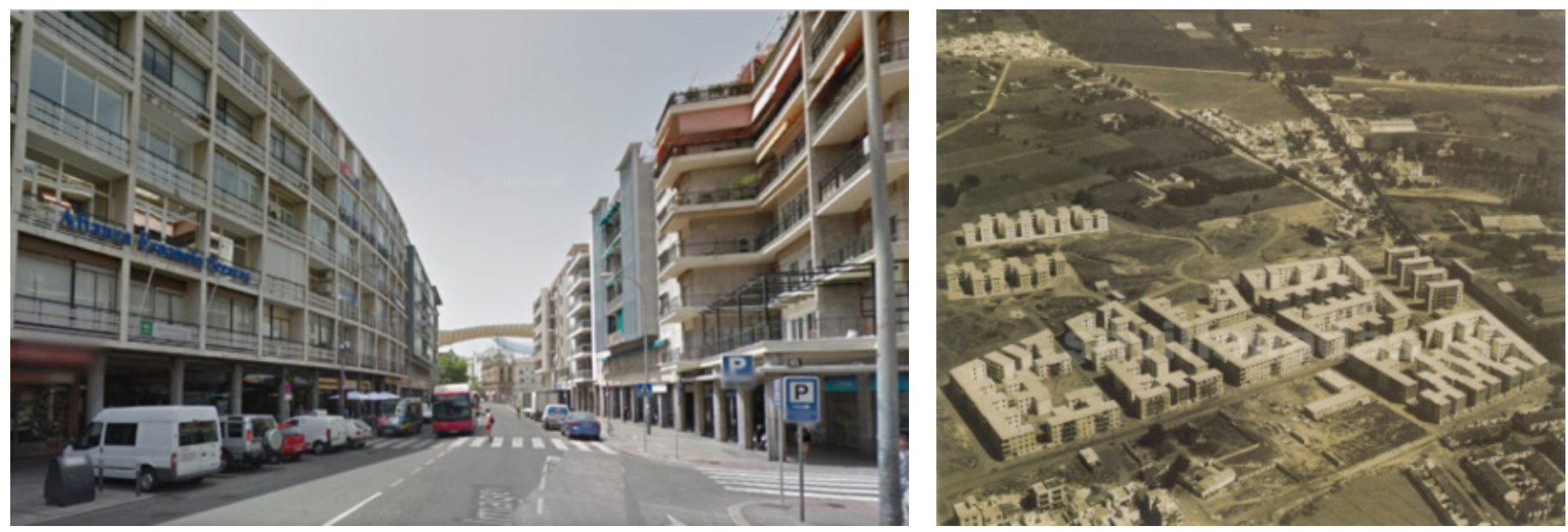
rencia de las fachadas urbanas, y se impuso un lenguaje estético liso sin tomar en cuenta ni siquiera el entorno inmediato. Un paseo bajo una reposada observación por las calles históricas hace posible constatar lo dicho.

El espacio público es el espacio percibido y vivido por todos pero gestionado en teoría por quienes han recibido nuestra representación, sin embargo estos responden más a las demandas de quienes ahora identifican como los "agentes que participan en la construcción de la ciudad": propietarios, promotores, inversores, constructores, administración pública. En esta situación, el ciudadano quedaba convertido en simple consumidor, también del espacio urbano en el que se hace ostensible el libre mercado con una amplia y siempre novedosa oferta en la que el neuromárquetin es un recurso eficiente.

A fines del siglo pasado el significado y el contenido de la ciudad entran en la crisis descrita al principio de este artículo. La ciudad de la $3 \mathrm{C}$ ha pasado a ser la actual, que la denomino de las $4 \mathrm{D}$ (distinta, dispersa, despilfarradora y depredadora) (figuras 25 y 26), cuyo estado es producto de radicales transformaciones de la sociedad con índices de concentración de riqueza y de pobreza nunca antes conocidos, tal como ya se aprecia en las denominadas megaciudades y en los corredores urbanos presentes en todos los continentes. Realidad urbana en el planeta que da lugar a preguntarnos: ¿La ciudad que hemos conocido ha muerto, está agónica, ha fracasado o está en crisis? ¿En síntesis, cuá-
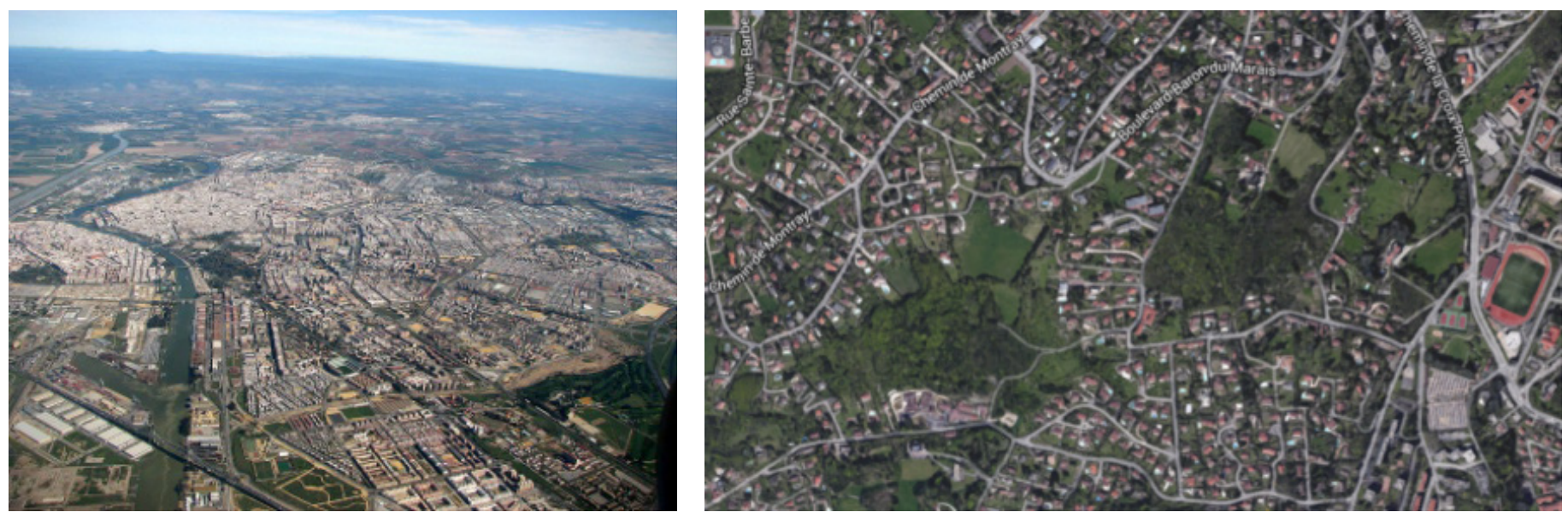

les han sido los cambios del espacio público?

El siglo XX comenzó con el anuncio de Nietzsche de que Dios había muerto igual que el arte clásico en manos de las vanguardias y terminó con el fin de las utopías revolucionarias, de la producción en cadena, e incluso con la muerte de la ciudad que advirtieron Jacobs y Choay. El siglo XXI ha comenzado bajo los efectos de las continuas revoluciones del conocimiento y de las tecnologías vinculadas a las demandas del mercado y del consumo. Es un sarcasmo que ahora los objetos han comenzado también a ser inteligentes; incluida la ciudad.

El París de Haussmann hizo posible que plazas y calles se convirtieran en foros de expresión social, de manifestaciones y hasta de revoluciones, sin descuidar que la ciudad fuese bella.

Con el Movimiento Moderno de la Arquitectura, la supresión de la calle, substituida por la vía conformada por bloques aislados, como se ha señalado, apareció un espacio comunitario, no público y tampoco privado.

En las últimas décadas ha emergido un nuevo tipo de espacio pú- $\pi$ Figura 25. Ciudad de la 3C. Sevilla. Fuente: disponible en https:// es.wikipedia.org/wiki/Sevilla\#/media/ File:Sevilla_Luft_120308.JPG.

त Figura 26. Ciudad de las 4D. Lyon. Fuente: disponible en https://www.google.es/maps/place/Lyon,+Francia/@4 $5.7565311,4.7649807,12126 \mathrm{~m} / \mathrm{dat}$

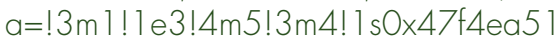
bae88797:0x408ab2ae4bb2 1 fo! $8 \mathrm{~m} 2$ ! 3d45.764043!4d4.835659 
blico: "espacio concesionado" (figuras 27 y 28), es decir, de propiedad o de dominio público que se entrega a la empresa o iniciativa privada bajo condiciones y plazos determinados. Es el de las Setas de Sevilla, una plaza pública concesionada, y de otros equipamientos: los empresarios invierten en la construcción en una parcela pública y gestionan en su beneficio durante varias décadas. Numerosos equipamientos deportivos y aparcamientos están en esta situación.

Finalmente, con la presencia del "espacio de los flujos" (Internet), el espacio público adquiere una nueva connotación. Paul Virilio lo había extendido solo a la televisión. Ahora se encuentra en todo tipo de pantallas de manera indiscriminada: móviles, tablets, ordenadores. De esta forma, el espacio público ya no es únicamente el escenario físico, calles y plazas donde la sociedad, corporalmente, se hace visible, se encuentra y genera opinión pública, que por otra parte merece la atención del urbanista, del arquitecto y del artista. A la dimensión cultural, acaba de integrarse otra. Aquella dimensión virtual con la que el espacio público se hace patente en las Redes. Así es cómo el espacio público se convierte a la vez en contenedor y en contenido, el espacio del ser (cultura) y del estar (lugar), una entidad con un entorno que ha devenido en espacio híbrido: ${ }^{10}$ sociofísicovirtual conformado por cuerpos, escenarios físicos y redes; sin límites, con acceso indiscriminado incluso a los bebés.

En el espacio público híbrido, el protagonista ya no es el ciudadano, ni es el pueblo ni es la masa; es la multitud (Negri y Hardt, 2004) en cuanto esta no es representable, pero a la vez, resulta ser para bien, una expresión de la inteligencia colectiva, ostensible en las acciones e
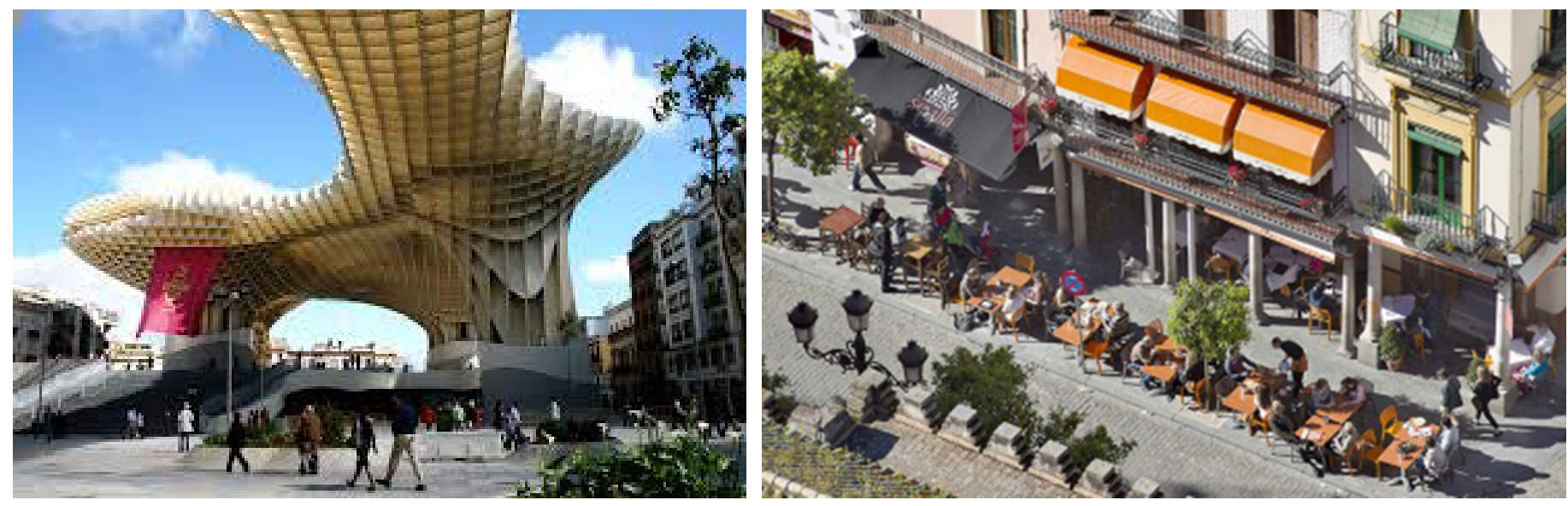

Figuras 27 y 28 . Espacios urbanos concesionados en Sevilla. Fuente: fotografías del autor.

10 Benavides Solís, Jorge, 15M Spanish revolution. 2011. http://issuu.com/jorgebs/docs/15m_spanish_revolution.

11 https://vimeo.com/111579945 Tweeting and moving around. A day of trips in Spain. Espacio de flujos. iniciativas que son producto de la "comunicación en $\operatorname{Red} " 11(15 \mathrm{M})$, y para mal, un disolvente, un dispersor de cuerpos y de cálidos afectos corporales (figuras 29-32).

En estas condiciones el nuevo espacio público con una dimensión inmaterial, es de todos y es de nadie, en cualquier caso funcional para el idiotes griego, para el des-comprometido con la ciudad: consumidor o cliente; dos individualidades que han suplantado al ciudadano, "especie en peligro de extinción".

Llegados a este punto reafirmo: una ciudad sin ciudadanos y sin espacio público no es posible.

El espacio público que en su primigenio origen fue al mismo tiempo colectivo, sagrado y aglutinador, se hizo ágora, foro, plaza, centro e imprescindible componente de la ciudad porque, repito, la ciudad sin espacio público es simple urbanización; no tiene polis. Una urbanización 

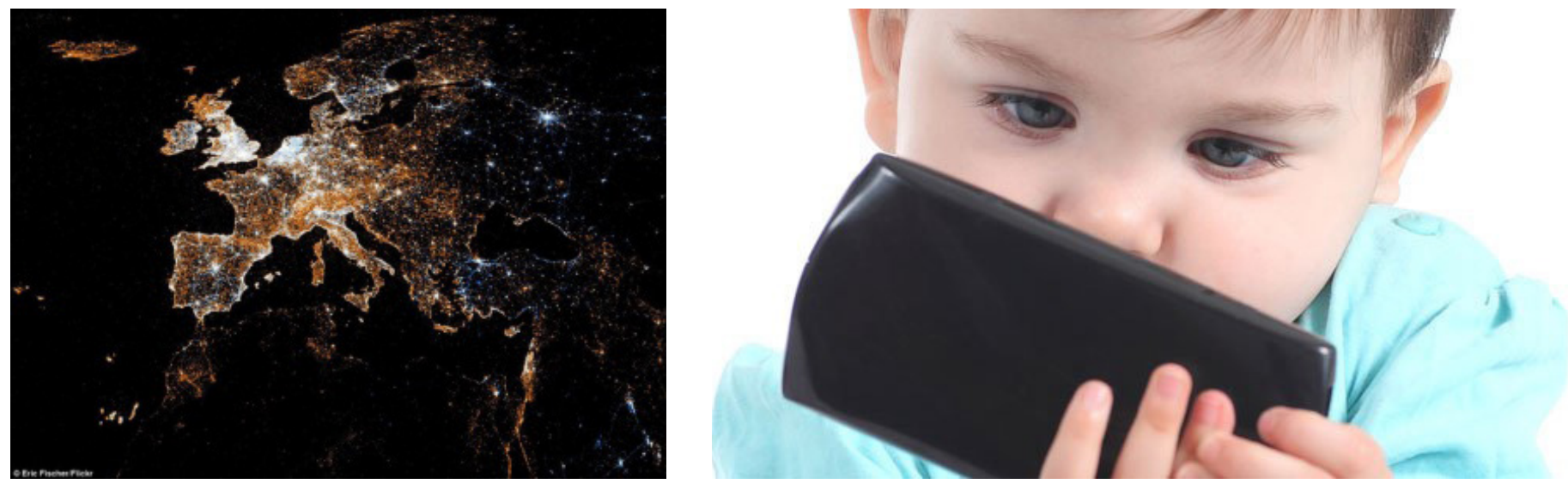
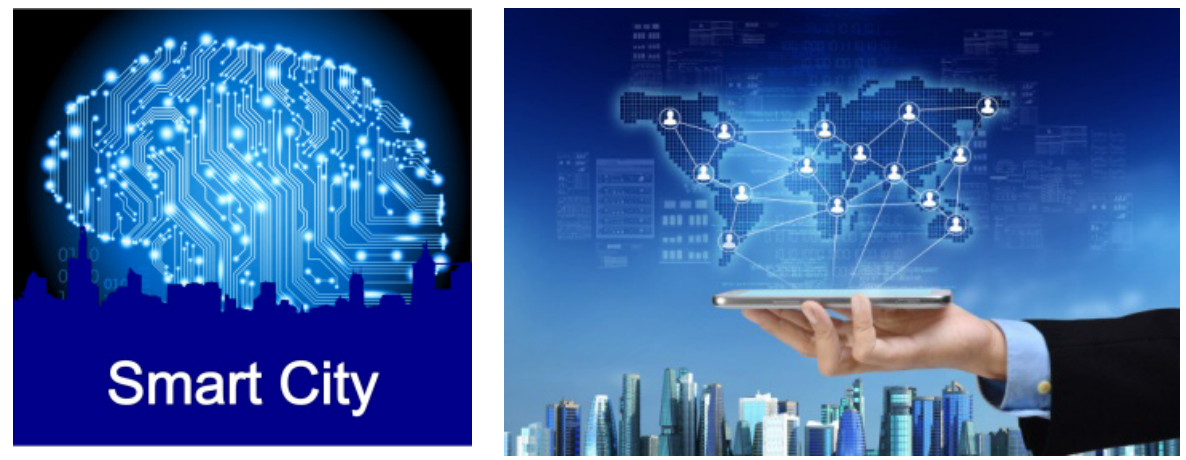

privada con baja densidad y extensas parcelas, no tiene necesidad de equipamientos públicos porque los tiene completos, de su propiedad.

El espacio público como tradicionalmente lo hemos entendido está en peligro de extinción porque las formas de producción, de distribución, de uso y de consumo han cambiado radicalmente. Ya no dependen solamente de los recursos materiales y del hombre, sino de las herramientas e instrumentos que él mismo ha diseñado.

Asumiendo que la ciudad, sin lugar a dudas, es el bien cultural más complejo que construye la sociedad, el nuevo espacio público ahora se encuentra cargado de numerosos matices antes inexistentes, que a partir del uso de las TIC, se han ido incorporando a una sorprendente velocidad, dejándonos un tiempo de adaptación cada vez más corto.

Pero, aun así, el espacio público para habitar (Benavides, 2013) ${ }^{12}$ habría que asumirlo más bien como una reivindicación social trans-disciplinar, siempre y cuando, aun contando con el ilimitado espacio de los flujos, nos concedamos la posibilidad de cohabitar, de con-vivir en una sociedad de ciudadanos y no en agrupaciones de simples clientes o consumidores sometidos al poder.

Una reivindicación del espacio público del ser y del estar en el ámbito de todos los componentes primigenios que supone la ciudad (urbs, civitas y polis): aquel físico (calles, plazas, jardines, parques, bosques, equipamientos), social (derechos y servicios básicos, el arte, la cultura) y político (participación democrática proactiva en el gobierno) (Benavides, 2009).
๙ Figura 29. Espacio híbrido sociofísico-virtual. Fuente: disponible en http:// 1 .bp. blogspot.com/-9SPOaoJGdko/VnY2nSFjBRI/AAAAAAAAC4U/ uTwJLNcpP28/s 1600/Europe-Big.jpg.

入 Figura 30. Espacio tweeter. Fuente: disponible en http://www.guiainfantil.com/articulos/educacion/ nuevas-tecnologias/10-motivos-para-prohibir-los-smartphone-a-ninos-menores-de12-anos/.

$\leftarrow$ Figuras 31 y 32 . Espacio hibrido socio-físico-virtual. Ciudad inteligente. Fuente: disponible en http: / / www.iottechworld.com/smart-city/smart-city-applications-for-an-urban-lifestyle.html y http:/ / www.codigonexo.com/wp-content/ uploads/2016/04/smartcity-citizen.jpg.

12 En el principio fue el entorno, el espacio libre, el paisaje, en palabras que insinúa Heidegger, el río cuando aún no tenía puente (el campo cuando aún no tenía vallas). Pero habitar es construir (los dos verbos en alemán participan del mismo origen), lo cual a la vez significa: ser, permanecer en un lugar, delimitar; pero teniendo en cuenta que un límite no es eso en lo que algo se detiene, como reconocían los griegos sino que es aquello a partir de lo cual algo inicia su presencia (Benavides, 2013). 


\section{Bibliografía}

Adame Goddard, J. (2009). Curso de derecho romano clásico. México: http://works.bepress.com/jorge_adame_goddard/.

Benavides Solís, J. (2013). La Herencia cultural. Conceptos clave para la protección.

Benavides Solís, J. (2009). Planeamiento, gestión y democracia en la construcción de la ciudad. Práctica urbanistica. Revista mensual de urbanismo, 85, 59-73.

García Chic, G. (Coord). (2014). Historia de Europa (ss. $X$ a. $C-V d$. C. .). Sevilla: Universidad de Sevilla.

Gideon, S. (1982). Espacio, Tiempo y Arquitectura. Madrid: Reverté.

Mellaart, J. (1967). Çatal Hüyük, a Neolithic Town in Anatolia. Nueva York: McGraw-Hill.

Mellaart, J. (1967). Anatolia: before c. 4000 B.C. and c.
2300-1750 B.C. Cambridge: Cambridge University Press.

Migayrou, F. (ed.). (2012). La tendenza: Italian architectures, 1965-1985. Paris: Centro Pompidou.

Negri, T. y Hardt, M. (2004). Multitud: guerra y democracia en la era del imperio. Madrid: Debate.

Pirenne, H. (1983). Las ciudades de la Edad Media. Madrid: Alianza.

Polibio de Megalópolis. Historia Universal Bajo la República Romana, Libro VI, Cap. X.

Venturi, R. (1966). Complejidad y contradicción en Arquitectura. Barcelona: Gustavo Gili.

Weber, M. (1987). La ciudad. Madrid: Las Ediciones de Las Piqueta.

BENAVIDES SOLÍS, Jorge. Sin espacio público no hay ciudad. Hábitat y Sociedad, 2016, n. ${ }^{\circ}$ 9, pp. 177-192.

$<$ www.habitatysociedad.us.es>

http://dx.doi.org/10.12795/HabitatySociedad.2016.i9.09

$\bigcirc$ 